\title{
Physical (in)activity dependent structural plasticity in bulbospinal catecholaminergic neurons of rat rostral ventrolateral medulla
}

\author{
Nicholas A. Mischel ${ }^{1}$, Ida J. Llewellyn-Smith ${ }^{1,2}$, and Patrick J. Mueller ${ }^{1}$ \\ ${ }^{1}$ Department of Physiology, Wayne State University School of Medicine, Detroit, MI 48201 USA \\ ${ }^{2}$ Cardiovascular Medicine, Physiology and Centre for Neuroscience, School of Medicine, Flinders \\ University, Bedford Park, South Australia 5042 Australia
}

\begin{abstract}
Increased activity of the sympathetic nervous system is thought to play a role in the development and progression of cardiovascular disease. Recent work has shown that physical inactivity versus activity alters neuronal structure in brain regions associated with cardiovascular regulation. Our physiological studies suggest that neurons in the rostral ventrolateral medulla (RVLM) are more responsive to excitation in sedentary versus physically active animals. We hypothesized that enhanced functional responses in the RVLM may be due, in part, to changes in the structure of RVLM neurons that control sympathetic activity. We used retrograde tracing and immunohistochemistry for tyrosine hydroxylase (TH) to identify bulbospinal catecholaminergic (C1) neurons in sedentary and active rats after chronic voluntary wheel-running exercise. We then digitally reconstructed their cell bodies and dendrites at different rostrocaudal levels. The dendritic arbors of spinally-projecting TH neurons from sedentary rats were more branched than those of physically active rats $(\mathrm{p}<0.05)$. In sedentary rats, dendritic branching was greater in more rostral versus more caudal bulbospinal $\mathrm{C} 1$ neurons whereas, in physically active rats, dendritic branching was consistent throughout the RVLM. In contrast, cell body size and the number of primary dendrites did not differ between active and inactive animals. We suggest that these structural changes provide an anatomical underpinning for the functional differences observed in our in vivo studies. These inactivity-related structural and functional changes enhance the overall sensitivity of RVLM neurons to excitatory stimuli and may contribute to an increased risk of cardiovascular disease in sedentary individuals.
\end{abstract}

\section{Graphical abstract}

Physical inactivity versus activity is associated with functional changes in control of blood pressure by neurons in the rostral ventrolateral medulla (RVLM). Here, the authors show that putative cardiovascular RVLM neurons have more complex dendrites in inactive versus active rats. This anatomical difference may underpin the functional differences previously reported.

Correspondence to: Patrick J. Mueller, Ph.D., Department of Physiology, Wayne State University School of Medicine, 540 E. Canfield, Detroit MI 48201, Phone: 313-577-1559, Fax: 313-577-5494, pmueller@ med.wayne.edu.

Conflict of Interest: There are no conflicts of interest to report. 


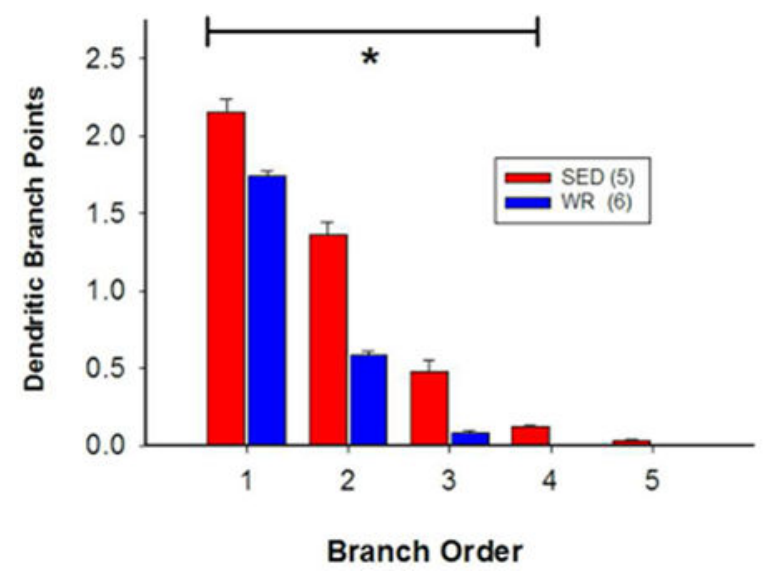

\section{Keywords}

Sympathetic nervous system; sedentary; neuroplasticity

\section{Introduction}

According to the Global Health Observatory, a data collection arm of the World Health Organization, hypertension is responsible for $12.8 \%$ of deaths worldwide (Global Health Observatory, 2013). It is well established that physical inactivity contributes independently to many cardiovascular diseases, including hypertension (Blair, 2009; Danaei et al., 2009). Increased activity in the sympathetic nervous system is a hallmark of hypertension (Grassi, 2010) and it is possible that physical inactivity alone may contribute to the development of hypertension by raising sympathetic activity (Mueller, 2010).

The rostral ventrolateral medulla (RVLM) contains neurons that are integral to control of sympathetic nerve activity and blood pressure (Guyenet, 2006; Schreihofer and Sved, 2011). These neurons make monosynaptic connections with sympathetic preganglionic neurons (SPN) in the intermediolateral cell column (IML) of the spinal cord and can directly regulate sympathetic outflow and thereby vascular tone (Deuchars et al., 1995; Zagon and Smith, 1993). Cardiovascular responses to activation of RVLM neurons are increased in animals with cardiovascular disease (Adams et al., 2007; Bergamaschi et al., 1995; Ito et al., 1999; Stocker et al., 2007) and in physically inactive animals (Martins-Pinge et al., 2005; Mischel and Mueller, 2011; Mueller, 2007). In some animal models of hypertension, vascular tone in the splanchnic bed seems to be particularly important (Osborn et al., 2011). In fact, increased splanchnic sympathetic tone supports blood pressure in different forms of hypertension (Huber and Schreihofer, 2011; King et al., 2007). Furthermore, we have shown that, compared to physically active rats, sedentary rats show enhanced splanchnic sympathetic nerve responses to direct stimulation of the RVLM (Mischel and Mueller, 2011). In view of these data, we have hypothesized that changes in the function of RVLM neurons that regulate splanchnic sympathetic outflow contribute to the development of hypertension. 
Structural and functional neuroplasticity in the CNS occur in response to voluntary wheel running exercise (Farmer et al., 2004; Van Praag et al., 1999). In particular, voluntary wheel running affects the dendritic morphology of neurons in cardiorespiratory centers within the CNS (Nelson and Iwamoto, 2006; Nelson et al., 2005; Nelson et al., 2010). Since dendritic outgrowth is associated with synapse formation and maturation (Flavell and Greenberg, 2008), increased dendritic branching of cardiovascular RVLM neurons could at least partially explain why sedentary animals have enhanced resting splanchnic sympathetic tone and resting blood pressure (Flavell and Greenberg, 2008; Mischel and Mueller, 2011). We hypothesize that physical inactivity may increase sympathetic nerve activity by altering the structure of bulbospinal neurons in the RVLM, specifically through an increase in dendritic branching and/or an increase in the size of their cell bodies. These structural changes would be consistent with an increase in excitability of bulbospinal RVLM neurons.

The purpose of this study was to analyze the somatic morphology and dendritic branching patterns of adrenergic $(\mathrm{C} 1)$ bulbospinal neurons in the RVLM. Along with non-adrenergic (non-C1) bulbospinal neurons, $\mathrm{C} 1$ neurons regulate sympathetic outflow through their inputs to SPN in the spinal cord (Schreihofer and Sved, 2011). Specifically, we examined C1 neurons that had been retrogradely labelled from the lower thoracic cord. SPN in this region are known to project to the coeliac and superior mesenteric ganglia (Strack et al., 1988), which contain almost all of the postganglionic neurons that provide sympathetic innervation to the mesenteric vasculature (Hsieh et al., 2000) as well as to the stomach and small intestine (Quinson et al., 2001; Trudrung et al., 1994). We compared results from sedentary rats versus physically active rats that ran voluntarily on in-cage running wheels. We examined rats after 11-12 weeks of activity or inactivity so that we could make direct correlations with data from our previous physiological study in which rats were assessed after 10-13 weeks of activity or inactivity (Mischel and Mueller, 2011). We digitally reconstructed bulbospinal $\mathrm{C} 1$ neurons located in the traditional RVLM, the region bounded by the pyramidal tract, the spinal trigeminal tract, the nucleus ambiguus, and 600 micrometers caudal to the facial nucleus (Schreihofer and Sved, 2011). We also examined neurons just ventral and medial to the facial nucleus (FN) up to 450 micrometers rostral to its caudal pole because of our recent anatomical evidence that neurons in this area are a significant fraction of the bulbospinal C1 population (Llewellyn-Smith and Mueller, 2013). Our present results show that, after chronic inactivity versus activity, the complexity of the dendritic fields of putative cardiovascular C1 neurons in RVLM increases but there is no change in somatic morphology or in the number of primary dendrites. In addition, bulbospinal $\mathrm{C} 1$ neurons from sedentary animals exhibited increased dendritic branching in rostral versus caudal regions of the RVLM whereas dendritic branching in C1 neurons from physically active rats was consistent along the entire rostrocaudal extent of the RVLM.

\section{Methods}

All methods were approved by the Institutional Animal Care and Use Committee of Wayne State University and carried out according to the American Physiological Society's "uiding Principles in the Care and Use of Animals". Food (Purina LabDiet \#5001, Purina Mills, Richmond, IN) and tap water were provided to the animals ad libitum. 


\section{Daily Spontaneous Running}

For these studies, we used male Sprague-Dawley rats (Harlan, Indianapolis, IN, n=11) weighing 75-100 g ( $\sim 4$ weeks of age) at the time of delivery to Wayne State University. Animals were housed in AALAC-accredited facilities (i.e., controlled light and temperature) with 12:12 hour light:dark cycles beginning at 7 am:7 pm EST, respectively. Animals were placed individually in standard cages with or without running wheels (Tecniplast, Eaton, PA; wheel diameter $34 \mathrm{~cm}$ ) for 11-12 weeks (physically active group, $\mathrm{n}=6$; sedentary group, $\mathrm{n}=5$ ). Daily and cumulative running data were recorded with bicycle computers (Sigma Sport, Olney, IL) calibrated to the diameter of the running wheels.

\section{Spinal Cord Injections of Retrograde Tracer}

Prior to spinal cord injections, active and sedentary rats were paired randomly and coded so that the researchers who perfused the rats, processed the tissue, and collected the data were blinded as to whether rats were sedentary or active. Once all data had been collected, the identification code of each animal was used to separate sedentary and active rats into their respective groups for data analysis.

Pairs of sedentary and active rats received spinal cord injections on the same day in order to minimize day-to-day experimental variability across groups. The injection protocol was as described previously (Llewellyn-Smith and Mueller, 2013). Briefly, isoflurane-anesthetized rats were placed in a stereotaxic apparatus with a spinal attachment (Kopf Instruments, Tujunga, CA). A laminectomy was performed at vertebral level T9, exposing the T10 spinal cord segment. Three injections ( $60 \mathrm{nl}$ each) of cholera toxin B subunit (CTB, $1 \%$ in distilled water, List Biological Laboratories, Campbell, CA) targeting the IML were made along the rostrocaudal extent of T10 on each side of the cord (6 injections total). Three sedentary and three active rats received spinal cord injections after 11 weeks of running, and three sedentary and three active rats received spinal cord injections after 12 weeks of running. One sedentary rat in the first group of animals died during spinal cord injection surgery. This rat was not replaced so that there was one unpaired active rat in the study. One additional rat, which was not part of either the active or the sedentary group, received similar spinal CTB injections. Rats recovered for one week after tracer injection. They received pain relief (Ketofen subcutaneous, $5 \mathrm{mg} / \mathrm{kg}$, Fort Dodge Animal Health, Fort Dodge, IA) once a day for two days following surgery and were monitored daily for normal ambulation and grooming. After tracer injection and on the same day as the surgery, rats in the active group were returned to cages containing running wheels.

\section{Perfusion and Tissue Processing}

One week after CTB injections, all rats were perfused with $500 \mathrm{~mL}$ tissue culture medium (Dulbecco's Modified Eagle's Medium/ Ham's F12, Catalogue \#D-8900; Sigma, St. Louis, $\mathrm{MO}$ ) followed by $1 \mathrm{~L}$ of fixative ( $4 \%$ formaldehyde in $0.1 \mathrm{M}$ phosphate buffer, $\mathrm{pH}$ 7.4). Brains and spinal cords were removed and post-fixed for 3-4 days. Spinal cords were washed and stored in $0.1 \mathrm{M}$ phosphate buffer with $0.05 \%$ sodium azide at $4^{\circ} \mathrm{C}$ until injection sites were located. Brains were washed in $0.1 \mathrm{M}$ phosphate buffer, $\mathrm{pH} 7.4$, and briefly stored at $4{ }^{\circ} \mathrm{C}$ until blocking and sectioning. Brainstems from pairs of sedentary and active rats were given different marks and then blocked from the spinomedullary junction to the 
cerebromedullary interface. Pairs of blocks were individually embedded in agarose gel and transversely sectioned at $150 \mu \mathrm{m}$ on a Vibratome (Leica Microsystems, Buffalo Grove, IL) into Corning Netwells ${ }^{\circledR}$ (Fisher Scientific, Pittsburgh, PA) so that each well contained brainstem sections from both rats. The brainstem of the additional rat, which was not part of either the active or sedentary group, was sectioned at $50 \mu \mathrm{m}$ to provide better documentation of the distribution of bulbospinal catecholaminergic RVLM neurons. Sections were stored in $0.1 \mathrm{M}$ phosphate buffer with $0.05 \%$ sodium azide at $4^{\circ} \mathrm{C}$ until immunohistochemical processing.

\section{Immunohistochemistry}

Immunohistochemical staining and resin embedding of $150 \mu \mathrm{m}$-thick sections from the 6 active and 5 inactive rats used for quantification were performed according to LlewellynSmith and Gnanamanickam (2011). Briefly, brainstem sections from each pair of active and sedentary rats were processed in the same containers so that sections underwent identical processing. Sections were exposed to $10 \mathrm{mM}$ Tris, $0.9 \% \mathrm{NaCl}, 0.05 \%$ thimerosal in $10 \mathrm{mM}$ phosphate buffer, pH 7.4 (TPBS) containing 0.3\% Triton X-100 (Sigma, St. Louis, MO) to improve antibody penetration and then to $30 \%$ methanol with $1 \%$ hydrogen peroxide to quench endogenous peroxidase activity. The sections were then incubated overnight in blocking buffer containing heat-inactivated Gibco ${ }^{\circledR} 10 \%$ normal horse serum (Life Technologies, Grand Island, NY) and then a rabbit primary antibody directed against TH (Millipore, Billerica MA) diluted 1:1,000 in 10\% NHS-TPBS-Triton at room temperature for five days on a shaker (Table 1). The sections were washed $3 \times 1$ hour in TPBS. Subsequent incubations in biotinylated anti-rabbit immunoglobulin (Jackson ImmunoResearch, West Grove PA) diluted 1:500 with 1\% NHS-TPBS-Triton and ExtrAvidin-horseradish peroxidase (Catalogue \#E-2886, Sigma) diluted 1:1500 in TPBSTriton, were performed at room temperature for five days with washes as above after each incubation. TH-immunoreactive neurons were revealed with an imidazole-enhanced diaminobenzidine reaction (Llewellyn-Smith et al., 2005), which produced a brown reaction product. To detect the retrogradely transported $\mathrm{CTB}$, we repeated the above procedure using a goat primary antibody against CTB (1:100,000 in 10\% NHS-TPBS-Triton; List Biological Laboratories; Table 1), an anti-goat secondary antibody (1:500 in 1\% NHS-TPBS-Triton) and ExtrAvidin-peroxidase. We detected CTB-immunoreactive neurons with the commercially available reaction substrate Vector SG (Vector Labs, Burlingame, CA), which produced a dark blue reaction product (Llewellyn-Smith et al., 2013). A 1:4 series of $50 \mu \mathrm{m}$ thick sections from the rat that was not part of the activity study were processed similarly except that incubation times were shorter (2 days in each primary antibody, overnight in each secondary antibody and 4-6 hours in avidin-HRP complex). Immunoreacted $150 \mu \mathrm{m}-$ thick sections from the 11 rats used for quantitative analysis were stored in $0.1 \mathrm{M}$ phosphate buffer with $0.05 \%$ sodium azide at $4^{\circ} \mathrm{C}$ until they were embedded in resin. The $50 \mu \mathrm{m}$-thick sections from the additional rat were mounted on gelatinized slides, dehydrated in graded alcohols, cleared in xylene, and coverslipped with Permount ${ }^{\circledR}$ (Fisher Scientific, Pittsburgh, PA). 


\section{Antibody Characterization}

We have previously shown that staining is eliminated when the List Biological Laboratories goat anti-CTB antiserum is absorbed with CTB (Llewellyn-Smith et al., 1995a).

A 1:1,000 dilution of the rabbit anti-TH produces a single band at approximately 62 kilodaltons by western blot of whole PC12 cell lysate (product sheet), rat heart tissue (Parrish et al., 2010) and in our laboratory using rat adrenal gland homogenate (data not shown). We and others have found that this $\mathrm{TH}$ antiserum stains somata, dendrites and axons with the expected distributions in rat brain (Chen et al., 2010; Llewellyn-Smith and Gnanamanickam, 2011).

\section{Embedding}

Immunostained sections from the 6 active and 5 inactive rats were embedded without osmication in Durcupan resin (Sigma) on glass slides using a modification of previously published procedures (Llewellyn-Smith and Gnanamanickam, 2011; Verberne and Llewellyn-Smith, 2013). Briefly, sections were rinsed in distilled water and slowly dehydrated in graded acetone solutions and then propylene oxide. Sections were subsequently exposed to a 1:1 mixture of propylene oxide and Durcupan ${ }^{\mathrm{TM}}$ resin before being infiltrated with undiluted resin overnight. Resin-infiltrated sections were arranged in serial order and embedded flat on clean glass slides under ACLAR ${ }^{\circledR}$ (ProSciTech, Thuringowa, Qld., Australia) coverslips. The resin was allowed to polymerize for 24 - 48 hours in an oven at $60^{\circ} \mathrm{C}$.

\section{Light Microscopy and Digital Reconstruction}

Immunohistochemically-labeled neurons in the RVLM were examined and photographed with either an Olympus BH-2 microscope (Olympus, Center Valley, PA) equipped with an MBF CX900 camera (Microbrightfield, Williston, VT), an Olympus BH-2 microscope equipped with a SPOT RT colour camera and SPOT RT software version 4.6 (SPOT Imaging Solutions, Sterling Heights, MI, USA), or a Nikon Eclipse Ci-L microscope and a SPOT Insight 2MP camera. The BH2 microscope with the MBF camera was also equipped with a motorized stage and Neurolucida software (Microbrightfield, Williston, VT) and was used to digitally reconstruct RVLM neurons that were immunostained for both CTB and TH. Criteria used to select neurons for reconstruction were 1) the double-labeled cell body was contained entirely within the section and was within the area bounded medially by the pyramidal tract, laterally by the spinal trigeminal tract, and dorsally by the nucleus ambiguus; and 2) the primary and secondary dendrites of the double-labeled neuron were contained entirely within the section and were not truncated. Using the caudal pole of the facial nucleus (FN) as our reference point (the section containing this landmark was termed FN0), we reconstructed neurons in each $150 \mu \mathrm{m}$-thick section that spanned from $600 \mu \mathrm{m}$ caudal (i.e. FN-4) to $450 \mu \mathrm{m}$ rostral (FN+3) of FN, where the number of bulbospinal $\mathrm{C} 1$ neurons decreases to nearly zero (Schreihofer and Guyenet, 2002). The reconstructed neurons all fell within an area bounded mediolaterally by the lateral edge of the pyramidal tract, the medial edge of the spino-trigeminal tract and dorsoventrally by the ventral edge of the compact formation of the nucleus ambiguus and the ventral surface of the medulla. 


\section{Confirmation of Placement of Injection Sites}

Injection placement was confirmed as previously published (Llewellyn-Smith and Mueller, 2013) with slight modification. Lower thoracic segments were removed from the perfused spinal cords of all rats. After embedding in albumin-gelatin (Llewellyn-Smith et al., 2007) and infiltration with sucrose, T9-T11 spinal segments from each rat were cut into $30 \mu \mathrm{m}$ thick sections on a cryostat. CTB-immunoreactivity in the spinal cord sections was revealed with a three-layer immunoperoxidase staining protocol and the reaction substrate Vector SG (Vector Labs, Burlingame, CA), which produced a dark blue reaction product (LlewellynSmith et al., 2013). Immunostained sections from each rat were analyzed to determine the location of the center of the injection site and three dimensional spread of injectate.

\section{Statistical Analyses}

To assess differences in morphology between physically active and inactive rats, we used SigmaStat v3.5 (Systat Software, San Jose, CA) and compared the area of the cell body, total number of dendritic branch points, and total dendritic length as well as data from Sholl analyses (total intersections with a series of circles placed at $10 \mu \mathrm{m}$ intervals from the soma). In consultation with our collaborating statistician (J. Ager, Ph.D., see Acknowledgements), we initially calculated overall average values for each group for comparison (see Table 2). This was accomplished by averaging morphological characteristics from individual neurons (4-10 per section) into a single value for each of 8 rostrocaudal sections (i.e., FN-4 through FN+3) from each rat. The resulting values for each individual section were then averaged to produce a single value for each rat. The average values for each rat were averaged for each group and the group average is reported with the standard error of the mean (see Table 2). Because we found significant differences in the number of branch points and total dendritic length, we performed additional comparisons using a similar strategy to that described above. These comparisons included total dendritic number and cell body aspect ratio, which is an indicator of the shape of the soma, as well as the total length of each order of dendritic branch (length of primary, secondary, tertiary, etc., branches) and the mean number of each order of branch. For each level of the Sholl analysis (i.e., increasing distance from the soma), we also assessed number of intersections, branch points, and dendritic length. Within-rat values for these morphological characteristics were averaged to yield a single value for each rat. Single values for each rat were again averaged to produce a group average for each characteristic, which we report with the standard error of the mean. Finally, in order to detect morphological differences based on rostrocaudal location as well as level of physical activity, we compared averaged values from neurons within each double-stained section (i.e., FN-4 through $\mathrm{FN}+3$ ) across groups.

Between group statistical comparisons of data averaged from neurons from all sections, such as those in Table 2, were performed using a 2-tailed Student's t-test. Data from Sholl analyses and data on dendrite branch order were evaluated using a mixed 2-way repeated measures ANOVA with physical activity level as Factor A and rostrocaudal level, distance from the cell body, or branch order as Factor B. We considered a p value of less than 0.05 as statistically significant. When significant interactions occurred, the Holm-Sidak method for multiple comparisons was employed post-hoc. 


\section{Treatment of Photomicrographs}

Adobe PhotoShop CS2 (Adobe Systems Incorporated, San Jose, CA) was used to size and sharpen digital images containing bulbospinal catecholaminergic neurons, construct montages, adjust contrast and brightness, equalize illumination, adjust color balance, match colors and prepare plates.

\section{Results}

In this study, we included data from 6 physically active, 5 sedentary rats and 1 additional rat whose activity level was not monitored. Physically active rats with an in-cage running wheel ran a total of $372 \pm 90 \mathrm{~km}$ (mean $+\mathrm{SEM} ; \mathrm{n}=6)$ over the 11-12 weeks of the study. On average, rats ran $4.73 \pm 1.11 \mathrm{~km} /$ day, at a speed of $46.2 \pm 4.0 \mathrm{~m} / \mathrm{min}$, for $115 \pm 26 \mathrm{~min} /$ day over the course of the study. The cumulative distance per day and duration per day are shown in Figure 1. After spinal cord surgery, rats resumed a consistent but lower level of voluntary activity $(1.2 \pm 0.6 \mathrm{~km} /$ day; $25 \%$ of baseline $)$ during the following 7 days, after which all rats were perfused for immunohistochemistry. Although the weights of the rats were similar at the beginning of the study (75-100 g), there was a significant difference in body weights between sedentary and active rats $(411 \pm 7 \mathrm{~g}$ vs. $355 \pm 10 \mathrm{~g}$, respectively) prior to perfusion at the end of the study. The additional rat was used to demonstrate the distribution of bulbospinal catecholaminergic RVLM neurons after spinal injection of CTB, perfusion and localization of CTB- and TH-immunoreactivity in sections thinner than those used for the quantitative analysis (i.e., $50 \mu \mathrm{m}$ rather than $150 \mu \mathrm{m}$ ).

\section{Placement of Spinal CTB Injections}

The placement of CTB injections was confirmed in 5 out of 6 active rats and 5 out of 5 sedentary rats. In these animals, the locations of the injection sites and the spread of CTB rostrocaudally and dorsoventrally was similar to our previous report (Llewellyn-Smith and Mueller, 2013). All injections were centered on the T10 IML and tracer was present in the IML region for approximately one spinal segment rostrally and approximately one spinal segment caudally. CTB-immunoreactivity also spread dorsoventrally through the dorsal horn along injection tracks.

\section{Distribution of Bulbospinal Catecholaminergic neurons in the RVLM}

The distribution of bulbospinal catecholaminergic neurons in the RVLM appeared to be the same in all rats, regardless of physical activity group, and varied according to rostrocaudal level.

In sections at (Figure 2) and rostral to the caudal pole of FN, many of the neurons with immunoreactivity for both CTB and TH occurred in a cluster just ventral and medial to the motor neurons of FN. This cluster of bulbospinal catecholaminergic neurons extended about 450 micrometers rostral to the caudal pole of FN. Neurons with CTB- and THimmunoreactivity were also present ventrally between the lateral cluster of $\mathrm{CTB} / \mathrm{TH}$ neurons and the pyramidal tract. In addition, a few neurons with staining for both CTB and TH were located just medial to FN and dorsal to the cluster of CTB/TH neurons. Caudal to the caudal pole of FN, neurons that were both CTB-positive and TH-positive did not occur in a tight 
cluster. Instead, in this part of the ventral medulla, double-labelled neurons were more homogeneously distributed in the region lying lateral to the pyramids, medial to the spinotrigeminal tract, and ventral to the compact formation of the nucleus ambiguus. All neurons reconstructed for the quantitative analysis were contained within these anatomical boundaries.

\section{Activity-related morphological differences in somata and dendrites}

From inspection of micrographs (Figures 3 and 4), we could not discern clear-cut anatomical differences between active and inactive rats in RVLM neurons that contained both immunoreactivity for TH and immunoreactivity for CTB. However, quantification of a variety of morphological parameters and Sholl analyses revealed that physical inactivity versus activity had a significant effect on the structure of the dendritic arbors of bulbospinal $\mathrm{C} 1$ neurons in the RVLM but not on their somata (Table 2).

We reconstructed a total of $382 \mathrm{CTB} / \mathrm{TH}$ neurons from sedentary rats $(76 \pm 1.7$ per rat; $\mathrm{n}=5$ rats) and $441 \mathrm{CTB} / \mathrm{TH}$ neurons from active rats $(74 \pm 3.3$ per rat; $n=6$ rats). On average, neurons from sedentary versus active animals had more dendritic branch points, greater total dendrite length, greater total dendritic surface area, and more intersections in Sholl analyses (Table 2). In contrast, there was no difference between sedentary and active rats in cell body perimeter, cell body area, cell body shape (i.e., aspect ratio), or the number of primary dendrites (Table 2).

Sholl analysis-Sedentary versus physically active conditions had a significant effect on the dendritic length and Sholl intersections of bulbospinal C1 neurons in RVLM and this effect depended on the proximity of a dendrite to the cell body (Figure 5). There was a significant main effect of activity level and distance from the cell body on both length and intersections ( $\mathrm{p}<0.001$ for both) as well as an interaction between distance from the cell body and activity level $(\mathrm{p}<0.001)$. Post hoc analyses revealed no difference in intersections in Sholl analyses or dendritic length close to the cell body (20-40 $\mu \mathrm{m})$. However, further away from the cell body (50-370 $\mu \mathrm{m})$, sedentary versus active rats had more intersections (Figure 5A) and increases in dendrite length (Figure 5B, $\mathrm{p}<0.05$ ).

Comparisons based on branch order-Because we reconstructed equal numbers of CTB/TH neurons in eight consecutive sections of the ventrolateral medulla (i.e.: $9.6 \pm 0.2$ vs. $9.2 \pm 0.4$ neurons/section in sedentary versus physically rats, respectively) we were able to make comparisons related to rostrocaudal distribution between groups. Sedentary versus physically active conditions had a significant effect on the number of dendrites and dendritic structure of bulbospinal C1 RVLM neurons and this effect depended on the branch order of the dendrites. There was a significant main effect of activity level and branch order on both parameters ( $\mathrm{p}<0.001$ for both) as well as an interaction between branch order and activity level $(\mathrm{p}<0.001)$. Post hoc analyses showed no difference in the number of primary dendrites between sedentary and active animals (Figure 6A, p=0.993). However, the number of secondary and higher-order dendrites was greater in inactive compared to active rats (Figure $6 \mathrm{~A}, \mathrm{p}<0.001)$. Primary dendrites were significantly shorter in sedentary relative to active rats, but higher-order dendrites were significantly longer in sedentary animals (Figure 6B, 
$\mathrm{p}<0.01$ ). In addition, the amount of branching in $1^{\text {st }}-4^{\text {th }}$ order dendrites was greater in sedentary compared to active rats $(\mathrm{p}<0.05)$.

Comparisons based on rostrocaudal location within the RVLM-The morphology of dendrites differed between sedentary and active rats depending on the rostrocaudal location of neurons within the RVLM (Figure 7A). The results from 2-way repeated measures ANOVA showed significant main effects of activity level and rostrocaudal location $(\mathrm{p}<0.01$ for both) as well as an interaction between physical inactivity versus activity and rostrocaudal level on the number of branch points $(\mathrm{p}<0.01)$. Post-hoc analyses revealed that, in sedentary versus active rats, neurons that were $300 \mu \mathrm{m}$ caudal to $450 \mu \mathrm{m}$ rostral to the caudal pole of FN had more branch points than neurons that occurred between $300 \mu \mathrm{m}$ and $600 \mu \mathrm{m}$ caudal to FN (Figure 7A, p <0.05). In contrast, there was no significant difference in branch points in the active group along the rostrocaudal axis (Figure 7A, $p>0.05$ ). For cell body area, there was a significant main effect of rostrocaudal level (Figure 7B, $\mathrm{p}<0.001$ ), no main effect of physical (in)activity, and no interaction between sedentary or physically active conditions. These data indicate that the most rostral CTB-positive $\mathrm{C} 1$ neurons are larger than the more caudal CTB-positive $\mathrm{C} 1$ neurons in both groups of animals. Lastly, for the number of primary dendrites, there was no significant main effect of group or rostrocaudal level nor was there a significant interaction (Figure $7 \mathrm{C}, \mathrm{p}>0.05$ ). These data indicate that there is no difference in the number of primary dendrites rostrocaudally or between sedentary and physically active rats.

\section{Discussion}

In this study, we used immunohistochemistry on $150 \mu \mathrm{m}$-thick tissue sections (LlewellynSmith and Gnanamanickam, 2011) and computer-based structural analysis to examine the effect of long-term physical inactivity versus voluntary activity on the structure of THimmunoreactive RVLM neurons retrogradely labeled with CTB from the T10 segment of the spinal cord. Our present results show how useful this approach can be for analyzing the detailed morphology of phenotypically-identified neuronal populations in the brain. In sections at and rostral to the caudal pole of FN, our quantitative analysis focused on the bulbospinal $\mathrm{C} 1$ neurons that occurred in a tight cluster ventromedial to FN. We chose to reconstruct many of these neurons because our previous study has shown that glutamate microinjections producing pressor responses were often located in sections containing facial motor neurons (Mischel and Mueller 2011). Thus, the most effective injection sites were coincident with the cluster of bulbospinal $\mathrm{C} 1$ neurons that we have analyzed here.

Our main findings are that the complexity of the dendritic fields of bulbospinal $\mathrm{C} 1$ presympathetic neurons is greater in sedentary versus physically active rats. In contrast, activity levels do not affect the number of primary dendrites arising from $\mathrm{C} 1$ neurons or the size and shape of their cell bodies. We also found that the degree to which activity versus inactivity affected dendritic morphology depended on the rostrocaudal location of $\mathrm{C} 1$ neurons within the RVLM. In sedentary rats, the dendrites of bulbospinal C1 neurons with cell bodies that lay close to FN had more branches than the dendrites of neurons more distant from and caudal to FN. In physically active rats, however, bulbospinal C1 neurons exhibited a consistent pattern of dendritic branching along the entire rostrocaudal extent of 
the RVLM. These findings support our original hypothesis that physical inactivity evokes changes in the dendritic arbors of bulbospinal C1 RVLM neurons in ways that may increase their excitability and resting activity but refute the contention that inactivity affects $\mathrm{C} 1$ cell bodies. Our data along with results from previously published in vivo studies (Becker et al., 2005; Martins-Pinge et al., 2005; Mischel and Mueller, 2011; Mueller, 2007; Mueller and Mischel, 2012) suggest that physical activity may decrease, and physical inactivity increase, the risk for cardiovascular disease in part via anatomical changes involving RVLM neurons.

We also identified a rostrocaudal variation in the morphology of spinally-projecting $\mathrm{C} 1$ neurons that was independent of the level of physical activity. In the most rostral sections that we analyzed, which were located about $450 \mu \mathrm{m}$ rostral to the caudal pole of FN, we found that the mean size of the cell bodies of bulbospinal $\mathrm{C} 1$ neurons was larger than for more caudally-located $\mathrm{C} 1$ neurons. The rostrocaudal difference in cell size was similar in both sedentary and physically active animals. A similar size difference between rostral and caudal C1 neurons has been reported in laboratory-housed (i.e., non-exercising) cats (Polson et al., 1992). There is also rostrocaudal variation in the neurochemical phenotypes of C1 neurons (Stornetta, 2009). More caudal C1 neurons that contain neuropeptide Y project to the hypothalamus whereas rostral C1 neurons are NPY-negative and spinally-projecting (Polson et al., 1992; Stornetta, 2009). Interestingly, the size of sympathetic postganglionic somata correlates with the size of the terminal fields of their axons (Purves et al., 1986). The complexity of sympathetic postganglionic dendrites also correlates with the number of preganglionic inputs that they receive (Purves et al., 1986). Taken together, if the same apply for bulbospinal $\mathrm{C} 1$ presympathetic neurons, then the more rostral neurons in this population would be more highly collateralized and/or project to a greater number of spinal segments than more caudal neurons and could also receive more synaptic input from sources yet to be identified.

\section{Bulbospinal Nerve Pathways Controlling Blood Pressure}

Almost three decades ago, $\mathrm{C} 1$ adrenergic neurons in the ventrolateral medulla were identified and early studies provided evidence that they play a critical role in the central control of blood pressure via their direct projections to autonomic regions of the thoracic spinal cord (Ross et al., 1984a; Ross et al., 1984b); reviewed by (Schreihofer and Sved, 2011). Subsequently, these $C 1$ presympathetic neurons were implicated in relaying various sympathetic reflexes and sympathoexcitatory responses (e.g., (Granata et al., 1985; Guyenet et al., 2001; Morrison and Reis, 1989). Both electrophysiological and anatomical studies have shown that blood pressure-sensitive $\mathrm{C} 1$ neurons in the RVLM provide glutamatergic input directly to SPN in the IML of thoracic spinal cord (Llewellyn-Smith et al., 1995a; Llewellyn-Smith et al., 1992; Morrison et al., 1991; Schreihofer and Sved, 2011; Stornetta et al., 2002). A series of studies have also examined the physiological effects of depleting bulbospinal $\mathrm{C} 1$ neurons in rats. These animals were found to have slightly decreased baseline blood pressure, attenuated baroreflex range, and substantially reduced responses to other sympathoexcitatory reflexes (Madden et al., 1999; Madden and Sved, 2003a;

Schreihofer and Guyenet, 2000; Schreihofer et al., 2000). Recently, the direct involvement of $\mathrm{C} 1$ neurons in sympathetic control of the cardiovascular system has been elegantly confirmed using selective transfection of catecholaminergic RVLM neurons with a viral 
vector that drives expression of the Drosophila inhibitory allatostatin receptor (Marina et al, 2011). Activation of this receptor in the RVLM of anesthetized rats decreased resting mean arterial pressure and renal sympathetic nerve activity, suggesting a tonic role for $\mathrm{C} 1$ neurons in control of sympathetic outflow (Marina et al, 2011). This population of presympathetic RVLM neurons was the focus of the present study.

As mentioned above, the RVLM contains a second population of bulbospinal presympathetic neurons that are involved in cardiovascular control, the bulbospinal non-C1 neurons (Madden and Sved, 2003b; Schreihofer and Guyenet, 1997; Schreihofer and Sved, 2011). These neurons were first identified in brainstem slices and found to have intrinsic pacemaker properties (Sun et al., 1988a; Sun et al., 1988b). Aside from the lack of catecholamine synthesizing enzymes, bulbospinal non-C1 neurons seem to have a similar neurochemical profile and distribution as C1 neurons in the RVLM (Stornetta, 2009), although we have recently shown that non-C1 bulbospinal neurons may be concentrated just rostral to the caudal pole of the facial nucleus (Llewellyn-Smith and Mueller, 2013). Although they represent the minority of bulbospinal cardiovascular RVLM neurons (Schreihofer and Guyenet, 1997), non-C1 neurons are still assumed to be very important in cardiovascular regulation because resting and some reflex-mediated sympathetic activity remain after depletion of C1 cells (Madden et al., 2006; Madden and Sved, 2003a; Schreihofer and Guyenet, 2000). In this study, we were not able to analyze activity-related morphological changes in the bulbospinal non-C1 presympathetic neurons because the perimeters of their cell bodies and dendrites were not adequately revealed by retrogradely transported CTB. When retrograde labeling in non-C1 neurons was light, CTB localized only in the Golgi apparatus and, when retrograde labelling was heavy, occurred only in somata and proximal dendrites. Because the spinally-projecting, non-C1 RVLM neurons have an important role in control of resting and reflex-mediated sympathetic activity, we aim to develop methods to study the structure and function of these neurons and others involved in sympathetic control. Our aim is to pinpoint cell groups that undergo activity-related plastic changes and therefore could become additional targets for anti-hypertensive therapies.

Sympathetic preganglionic neurons present in caudal thoracic spinal segments project to the coeliac, superior mesenteric, and aorticorenal ganglia as well as the adrenal gland (Moon et al., 2002; Strack et al., 1988; Strack et al., 1989). Sympathetic nerves originating from these ganglia provide innervation to the gastrointestinal tract and to mesenteric blood vessels (Hsieh et al., 2000; Li et al., 2013; Quinson et al., 2001; Trudrung et al., 1994). Recent publications have highlighted the importance of the splanchnic circulation for blood pressure control in normal and disease states (Fink, 2009; Huber and Schreihofer, 2011; Kuroki et al., 2012; Mischel and Mueller, 2011; Osborn et al., 2011). Thus, central neurons that control sympathetic outflow to the splanchnic vasculature could be an important target for future blood pressure-lowering therapies.

\section{Activity-related Changes in Bulbospinal cardiovascular circuitry and Disease Risk}

Persistent increases or decreases in the activity of neurons can cause long-lasting effects on neuronal structure, as has been well-documented in neural networks related to learning and memory (Caroni et al., 2012). "Activity-dependent plasticity" may also refer to an effect of 
chronic physical activity on those same neural networks (Van Praag, 2008). The anatomical features of neurons in brain regions associated with cardiovascular function also change in response to long-term physical activity (Michelini and Stern, 2009; Nelson et al., 2005). We and others have demonstrated that chronic physical activity also evokes functional changes in the RVLM neurons that control blood pressure and sympathetic outflow (Martins-Pinge et al., 2005; Mischel and Mueller, 2011; Mueller, 2007; Mueller and Mischel, 2012). These data led us to hypothesize that changes in the morphology of presympathetic RVLM neurons play a role in the differing cardiovascular responses that we have observed between sedentary and active rats; and this study has, in fact, demonstrated statistically significant differences in the dendritic arbors of spinally-projecting $\mathrm{C} 1$ neurons in sedentary compared to active rats. The results that we present here differ from the observations of the Iwamoto group (Nelson et al., 2005), who did not find any structural differences between RVLM neurons revealed by Golgi-Cox labeling in active versus inactive rats. This apparent conflict in results probably relates mainly to the fact that the Golgi-Cox method stains neurons randomly and indiscriminately. Hence, although the Golgi-Cox method allowed Nelson et al (2005) to examine and identify structural differences in other brain regions, their conclusions about the lack of change in a randomly stained, and undoubtedly functionally heterogeneous, pool of RVLM neurons does not appear to be applicable to the RVLM population that we examined in the present study. In contrast, our present study specifically targeted neurons within the RVLM that were both spinally-projecting and catecholaminesynthesizing, the classic definition of $\mathrm{C} 1$ presympathetic neurons. A further reason for the differences between our data and the data of Nelson et al. (2005) may be that they examined more caudal regions of the RVLM, where our study has shown that structural differences are less apparent. Also, it is possible that differences in tissue processing (i.e., perfusion fixation and immunohistochemistry versus immersion fixation and Golgi-Cox staining; Vibratome sectioning versus frozen sectioning on a sliding microtome) may have accounted for our ability to detect more intersections at the level of more distal dendrites than Nelson and colleagues (2005). With our methodology, which specifically targeted one neurochemical class of bulbospinal RVLM neuron and provided hundreds of cells for morphological analysis, we were able to make statistically meaningful conclusions about activity-related changes in the architecture of the somata and dendritic arbors of $\mathrm{C} 1$ presympathetic neurons.

Because of the importance of the splanchnic vasculature to blood pressure control, we chose to study RVLM neurons that project to SPN in the lower thoracic cord. We employed the retrograde tracer CTB injected at the T10 level to identify these neurons. A high proportion of C1 neurons in the RVLM project to the thoracic IML (Jeske and McKenna, 1992) and SPN providing input to the celiac, aorticorenal, and superior mesenteric sympathetic ganglia as well as to the adrenal gland are concentrated within the IML of T7-T12 (Strack et al., 1988). We found that, in general, sedentary rats showed an increase in dendritic branching in spinally-projecting C1 RVLM neurons. The CTB-labeled neurons that we studied could control one or all of the sympathetic outflows originating at the T10 level, which notably includes splanchnic, renal, and adrenal outflows. Although the physiology of spinallyprojecting C1 neurons has been well-studied (Schreihofer and Sved, 2011), we do not know the precise physiology of the neurons that we examined here. 
Sedentary compared to physically active rats show increased baseline renal sympathetic nerve activity (RSNA) (Negrao et al., 1993), and in sedentary rabbits and rats, baroreflexmediated activation of RSNA is increased (DiCarlo and Bishop, 1988; Negrao et al., 1993) compared to active animals. When we directly measured sympathetic output to the splanchnic circulation in a previous study, we found that there was a nearly two-fold increase in both resting and reflex-mediated splanchnic sympathetic nerve activity (SSNA) in sedentary versus active rats (Mischel and Mueller, 2011). Increased arterial pressure in hypertensive Zucker rats is maintained through increases in SSNA, possibly originating in the RVLM (Huber and Schreihofer, 2011). In the angiotensin II-salt model of rat hypertension, increased splanchnic tone seems to be a key contributor to the development of hypertension, whereas renal and lumbar sympathetic tone appear not to be involved (King et al., 2007; Osborn and Fink, 2010). For these reasons, this study focused specifically on C1 RVLM neurons that may innervate splanchnic and other abdominal SPN.

Since spinally-projecting $\mathrm{C} 1$ neurons play an important role in reflex-mediated sympathoexcitation during normal physiological conditions (see above), the activity of these neurons could be affected by, and might even contribute to, disease. Consistent with this suggestion, neurons within the RVLM show increased activation in various disease states, such as high salt diet, hyperinsulinemia, chronic renal failure, obesity, hypertension, and chronic heart failure (Adams et al., 2007; Bardgett et al., 2010; Dugaich et al., 2011; Huber and Schreihofer, 2011; Matsuura et al., 2002; Stocker et al., 2007; Wang et al., 2009). Moreover, C1 neurons have been specifically implicated as a population of RVLM neurons that shows increased activation in the two-kidney, one clip model of hypertension (Jung et al., 2004). We and others consider a sedentary lifestyle to be a disease state and an acute bout of exercise has been shown to cause either increased activation or recruitment of RVLM neurons in sedentary versus active animals (Ichiyama et al., 2002). Compared to active rats, sedentary rats also exhibit increased activation or recruitment of TH-positive RVLM neurons in response to acute stress (Greenwood et al., 2003). To our knowledge, the current study is the first to demonstrate differences in the morphology of the dendritic arbors of spinallyprojecting C1 RVLM neurons of sedentary compared to active rats. These structural changes could be one of the underlying mechanisms that mediate the increased activation of RVLM neurons in sedentary animals. If the central circuits controlling the cardiovascular system undergo similar morphological changes in humans, then neuroplasticity within the RVLM could provide one possible source of increased sympathetic activation in sedentary individuals and contribute to their increased risk of developing cardiovascular disease.

\section{Acknowledgments}

The authors thank Toni Azar from the Mueller laboratory for his technical expertise and contributions to this project. We thank Dr. Joel Ager from Wayne State University School of Medicine for input on statistical analyses. Thanks to Dr. Jose Rafols for helpful input on the structural analyses. We also thank the Neural Control of Cardiorespiratory Function Group at Wayne State University School of Medicine for their input during the development of this project.

Roles of authors: All authors had full access to all the data in the study and take responsibility for the integrity of the data and the accuracy of the data analysis. Study concept and design: NAM, IJLS, PJM. Acquisition of data: NAM, IJLS. Analysis and interpretation of data: NAM, IJLS, PJM. Drafting of the manuscript: NAM, IJLS, PJM. Critical revision of the manuscript for important intellectual content: NAM, IJLS, PJM. Statistical analysis: NAM. 
Obtained funding: PJM, NAM, IJLS. Administrative, technical, and material support: IJLS, PJM. Study supervision: PJM, IJLS.

Support: Award Number R01HL096787, National Heart, Lung, and Blood Institute, National Institutes of Health, to PJM; Project Grant \#1025031, National Health and Medical Research Council of Australia to AJM Verberne and IJLS. NAM was supported by a Fellowship \#F30-HL105003 from National Heart, Lung, and Blood Institute, National Institutes of Health. The content is solely the responsibility of the authors and does not necessarily represent the official views of the National Institutes of Health.

\section{Literature Cited}

Adams JM, Madden CJ, Sved AF, Stocker SD. Increased dietary salt enhances sympathoexcitatory and sympathoinhibitory responses from the rostral ventrolateral medulla. Hypertension. 2007; 50:354359. [PubMed: 17592069]

Bardgett ME, McCarthy JJ, Stocker SD. Glutamatergic receptor activation in the rostral ventrolateral medulla mediates the sympathoexcitatory response to hyperinsulinemia. Hypertension. 2010; 55:284-290. [PubMed: 20065145]

Becker LK, Santos RAS, Campagnole-Santos MJ. Cardiovascular effects of angiotensin II and angiotensin-(1-7) at the RVLM of trained normotensive rats. Brain Res. 2005; 1040:121-128. [PubMed: 15804433]

Bergamaschi C, Campos RR, Schor N, Lopes OU. Role of the rostral ventrolateral medulla in maintenance of blood pressure in rats with Goldblatt hypertension. Hypertension. 1995; 26:11171120. [PubMed: 7498979]

Blair SN. Physical inactivity: the biggest public health problem of the 21 st century. Br J Sports Med. 2009; 43:1-2. [PubMed: 19136507]

Caroni P, Donato F, Muller D. Structural plasticity upon learning: regulation and functions. Nat Rev Neurosci. 2012; 13:478-490. [PubMed: 22714019]

Chen D, Bassi JK, Walther T, Thomas WG, Allen AM. Expression of angiotensin type 1A receptors in $\mathrm{C} 1$ neurons restores the sympathoexcitation to angiotensin in the rostral ventrolateral medulla of angiotensin type 1A knockout mice. Hypertension. 2010; 56:143-150. [PubMed: 20458002]

Danaei G, Ding EL, Mozaffarian D, Taylor B, Rehm J, Murray CJ, Ezzati M. The preventable causes of death in the United States: comparative risk assessment of dietary, lifestyle, and metabolic risk factors. PLoS Med. 2009; 6:e1000058. [PubMed: 19399161]

Deuchars SA, Morrison SF, Gilbey MP. Medullary-evoked EPSPs in neonatal rat sympathetic preganglionic neurones in vitro. J Physiol. 1995; 487(Pt 2):453-463. [PubMed: 8558476]

DiCarlo SE, Bishop VS. Exercise training attenuates baroreflex regulation of nerve activity in rabbits. Am J Physiol. 1988; 255:H974-H979. [PubMed: 3177687]

Dugaich AP, Oliveira-Sales EB, Abreu NP, Boim MA, Bergamaschi CT, Campos RR. Role of the rostral ventrolateral medulla in the arterial hypertension in chronic renal failure. Int $\mathrm{J}$ Hypertens. 2011; 2010:219358. [PubMed: 21253520]

Farmer J, Zhao X, Van Praag H, Wodtke K, Gage FH, Christie BR. Effects of voluntary exercise on synaptic plasticity and gene expression in the dentate gyrus of adult male Sprague-Dawley rats in vivo. Neuroscience. 2004; 124:71-79. [PubMed: 14960340]

Fink GD. Arthur C. Corcoran Memorial Lecture. Sympathetic activity, vascular capacitance, and longterm regulation of arterial pressure. Hypertension. 2009; 53:307-312. [PubMed: 19114645]

Flavell SW, Greenberg ME. Signaling mechanisms linking neuronal activity to gene expression and plasticity of the nervous system. Annu Rev Neurosci. 2008; 31:563-590. [PubMed: 18558867]

Global Health Observatory. Raised blood pressure - Situation and trends. 2013

Granata AR, Ruggiero DA, Park DH, Joh TH, Reis DJ. Brain stem area with C1 epinephrine neurons mediates baroreflex vasodepressor responses. Am J Physiol. 1985; 248:H547-H567. [PubMed: 3985177]

Grassi G. Sympathetic neural activity in hypertension and related diseases. Am J Hypertens. 2010; 23:1052-1060. [PubMed: 20651696]

Greenwood BN, Kennedy S, Smith TP, Campeau S, Day HEW, Fleshner M. Voluntary freewheel running selectively modulates catecholamine content in peripheral tissue and c-fos expression in 
the central sympathetic circuit following exposure to uncontrollable stress in rats. Neuroscience. 2003; 120:269-281. [PubMed: 12849759]

Guyenet PG. The sympathetic control of blood pressure. Nat Rev Neurosci. 2006; 7:335-346. [PubMed: 16760914]

Guyenet PG, Schreihofer AM, Stornetta RL. Regulation of sympathetic tone and arterial pressure by the rostral ventrolateral medulla after depletion of C1 cells in rats. Ann N Y Acad Sci. 2001; 940:259-269. [PubMed: 11458683]

Hsieh NK, Liu JC, Chen HI. Localization of sympathetic postganglionic neurons innervating mesenteric artery and vein in rats. J Auton Nerv Syst. 2000; 80:1-7. [PubMed: 10742533]

Huber DA, Schreihofer AM. Altered regulation of the rostral ventrolateral medulla in hypertensive obese Zucker rats. Am J Physiol Heart Circ Physiol. 2011; 301:H230-H240. [PubMed: 21536848]

Ichiyama RM, Gilbert AB, Waldrop TG, Iwamoto GA. Changes in the exercise activation of diencephalic and brainstem cardiorespiratory areas after training. Brain Res. 2002; 947:225-233. [PubMed: 12176165]

Ito S, Gordon FJ, Sved AF. Dietary salt intake alters cardiovascular responses evoked from the rostral ventrolateral medulla. Am J Physiol Regul Integr Comp Physiol. 1999; 276:R1600-R1607.

Jeske I, McKenna KE. Quantitative analysis of bulbospinal projections from the rostral ventrolateral medulla: contribution of C1-adrenergic and nonadrenergic neurons. J Comp Neurol. 1992; 324:113. [PubMed: 1401261]

Jung JY, Lee JU, Kim WJ. Enhanced activity of central adrenergic neurons in two-kidney, one clip hypertension in Spague-Dawley rats. Neurosci Lett. 2004; 369:14-18. [PubMed: 15380299]

King AJ, Osborn JW, Fink GD. Splanchnic circulation is a critical neural target in angiotensin II salt hypertension in rats. Hypertension. 2007; 50:547-556. [PubMed: 17646575]

Kuroki MT, Guzman PA, Fink GD, Osborn JW. Time-dependent changes in autonomic control of splanchnic vascular resistance and heart rate in ANG II-salt hypertension. Am J Physiol Heart Circ Physiol. 2012; 302:H763-H769. [PubMed: 22114134]

Li M, Galligan JJ, Wang D, Fink GD. The effects of celiac ganglionectomy on sympathetic innervation to the splanchnic organs in the rat. Auton Neurosci. 2013; 154:66-73.

Llewellyn-Smith I, Pilowsky P, Minson JB, Chalmers J. Synapses on axons of sympathetic preganglionic neurons in rat and rabbit thoracic spinal cord. J Comp Neurol. 1995a; 354:193-208. [PubMed: 7782498]

Llewellyn-Smith IJ, DiCarlo SE, Collins HL, Keast JR. Enkephalin-immunoreactive interneurons extensively innervate sympathetic preganglionic neurons regulating the pelvic viscera. J Comp Neurol. 2005; 488:278-289. [PubMed: 15952166]

Llewellyn-Smith IJ, Gnanamanickam GJ. Immunoperoxidase detection of neuronal antigens in fullthickness whole mount preparations of hollow organs and thick sections of central nervous tissue. J Neurosci Methods. 2011; 196:1-11. [PubMed: 21167203]

Llewellyn-Smith IJ, Gnanamanickam GJ, Reimann F, Gribble FM, Trapp S. Preproglucagon (PPG) neurons innervate neurochemically identified autonomic neurons in the mouse brainstem. Neuroscience. 2013; 229:130-143. [PubMed: 23069752]

Llewellyn-Smith IJ, Martin CL, Fenwick NM, DiCarlo SE, Lujan HL, Schreihofer AM. VGLUT1 and VGLUT2 innervation in autonomic regions of intact and transected rat spinal cord. J Comp Neurol. 2007; 503:741-767. [PubMed: 17570127]

Llewellyn-Smith IJ, Mueller PJ. Immunoreactivity for the NR1 subunit of the NMDA receptor occurs in spinally-projecting catecholamine and serotonin neurons of the rat ventral medulla. Auton Neurosci. 2013 in press.

Llewellyn-Smith IJ, Phend KD, Minson JB, Pilowsky PM, Chalmers JP. Glutamate-immunoreactive synapses on retrogradely-labelled sympathetic preganglionic neurons in rat thoracic spinal cord. Brain Res. 1992; 581:67-80. [PubMed: 1354008]

Llewellyn-Smith IJ, Pilowsky P, Minson JB, Chalmers J. Synapses on axons of sympathetic preganglionic neurons in rat and rabbit thoracic spinal cord. J Comp Neurol. 1995b; 354:193-208. [PubMed: 7782498] 
Madden CJ, Ito S, Rinaman L, Wiley RG, Sved AF. Lesions of the C1 catecholaminergic neurons of the ventrolateral medulla in rats using anti-D $\beta H$-saporin. Am J Physiol Regul Integr Comp Physiol. 1999; 277:R1063-R1075.

Madden CJ, Stocker SD, Sved AF. Attenuation of homeostatic responses to hypotension and glucoprivation after destruction of catecholaminergic rostral ventrolateral medulla neurons. Am J Physiol Regul Integr Comp Physiol. 2006; 291:R751-R759. [PubMed: 16627690]

Madden CJ, Sved AF. Cardiovascular regulation after destruction of the $\mathrm{C} 1$ cell group of the rostral ventrolateral medulla in rats. Am J Physiol Heart Circ Physiol. 2003a; 285:H2734-H2748. [PubMed: 12933337]

Madden CJ, Sved AF. Rostral ventrolateral medulla C1 neurons and cardiovascular regulation. Cell Mol Neurobiol. 2003b; 23:739-749. [PubMed: 14514028]

Marina N, Abdala APL, Korsak A, Simms AE, Allen AM, Paton JFR, Gourine AV. Control of sympathetic vasomotor tone by catecholaminergic $\mathrm{C} 1$ neurones of the rostral ventrolateral medulla oblongata. Cardiovascuar Res. 2011; 91(4):703-710.

Martins-Pinge MC, Becker LK, Garcia MR, Zoccal DB, Neto RV, Basso LS, de Souza HC, Lopes OU. Attenuated pressor responses to amino acids in the rostral ventrolateral medulla after swimming training in conscious rats. Auton Neurosci. 2005; 122:21-28. [PubMed: 16139573]

Matsuura T, Kumagai H, Kawai A, Onimaru H, Imai M, Oshima N, Sakata K, Saruta T. Rostral ventrolateral medulla neurons of neonatal Wistar-Kyoto and spontaneously hypertensive rats. Hypertension. 2002; 40:560-565. [PubMed: 12364363]

Michelini LC, Stern JE. Exercise-induced neuronal plasticity in central autonomic networks: role in cardiovascular control. Exp Physiol. 2009; 94:947-960. [PubMed: 19617267]

Mischel NA, Mueller PJ. (In)activity-dependent alterations in resting and reflex control of splanchnic sympathetic nerve activity. J Appl Physiol. 2011; 111:1854-1862. [PubMed: 21979802]

Moon EA, Goodchild AK, Pilowsky PM. Lateralisation of projections from the rostral ventrolateral medulla to sympathetic preganglionic neurons in the rat. Brain Res. 2002; 929:181-190. [PubMed: 11864623]

Morrison SF, Callaway J, Milner TA, Reis DJ. Rostral ventrolateral medulla: a source of the glutamatergic innervation of the sympathetic intermediolateral nucleus. Brain Res. 1991; 562:126135. [PubMed: 1724740]

Morrison SF, Reis DJ. Reticulospinal vasomotor neurons in the RVL mediate the somatosympathetic reflex. Am J Physiol Regul Integr Comp Physiol. 1989; 256:R1084-R1097.

Mueller PJ. Exercise training attenuates increases in lumbar sympathetic nerve activity produced by stimulation of the rostral ventrolateral medulla. J Appl Physiol. 2007; 102:803-813. [PubMed: 17053106]

Mueller PJ. Physical (in)activity-dependent alterations at the rostral ventrolateral medulla: influence on sympathetic nervous system regulation. Am J Physiol Regul Integr Comp Physiol. 2010; 298:R1468-R1474. [PubMed: 20357021]

Mueller PJ, Mischel NA. Selective enhancement of glutamate-mediated pressor responses after GABA(A) receptor blockade in the RVLM of sedentary versus spontaneous wheel running rats. Front Physiol. 2012; 3:447. [PubMed: 23189062]

Negrao CE, Irigoyen MC, Moreira ED, Brum PC, Freire PM, Krieger EM. Effect of exercise training on RSNA, baroreflex control, and blood pressure responsiveness. Am J Physiol Regul Integr Comp Physiol. 1993; 265:R365-R370.

Nelson AJ, Iwamoto GA. Reversibility of exercise-induced dendritic attenuation in brain cardiorespiratory and locomotor areas following exercise training. J Appl Physiol. 2006; 101:1243-1251. [PubMed: 16794024]

Nelson AJ, Juraska JM, Musch TI, Iwamoto GA. Neuroplastic adaptations to exercise: neuronal remodeling in cardiorespiratory and locomotor areas. J Appl Physiol. 2005; 99:2312-2322. [PubMed: 16123206]

Nelson AJ, Juraska JM, Ragan BG, Iwamoto GA. Effects of exercise training on dendritic morphology in the cardiorespiratory and locomotor centers of the mature rat brain. J Appl Physiol. 2010; 108:1582-1590. [PubMed: 20339008] 
Osborn JW, Fink GD. Region-specific changes in sympathetic nerve activity in angiotensin II-salt hypertension in the rat. Exp Physiol. 2010; 95:61-68. [PubMed: 19717492]

Osborn JW, Fink GD, Kuroki MT. Neural mechanisms of angiotensin II-salt hypertension: implications for therapies targeting neural control of the splanchnic circulation. Curr Hypertens Rep. 2011; 13:221-228. [PubMed: 21298369]

Parrish DC, Alston EN, Rohrer H, Nkadi P, Woodward WR, Schutz G, Habecker BA. Infarctioninduced cytokines cause local depletion of tyrosine hydroxylase in cardiac sympathetic nerves. Exp Physiol. 2010; 95:304-314. [PubMed: 19880537]

Polson JW, Halliday GM, McAllen RM, Coleman MJ, Dampney RA. Rostrocaudal differences in morphology and neurotransmitter content of cells in the subretrofacial vasomotor nucleus. $\mathbf{J}$ Auton Nerv Syst. 1992; 38:117-137. [PubMed: 1377728]

Purves D, Rubin E, Snider WD, Lichtman J. Relation of animal size to convergence, divergence, and neuronal number in peripheral sympathetic pathways. J Neurosci. 1986; 6:158-163. [PubMed: 3944617]

Quinson N, Robbins HL, Clark MJ, Furness JB. Locations and innervation of cell bodies of sympathetic neurons projecting to the gastrointestinal tract in the rat. Arch Histol Cytol. 2001; 64:281-294. [PubMed: 11575424]

Ross CA, Ruggiero DA, Joh TH, Park DH, Reis DJ. Rostral ventrolateral medulla: Selective projections to the thoracic autonomic cell column from the region containing $\mathrm{C} 1$ adrenaline neurons. J Comp Neur. 1984a; 228:168-185. [PubMed: 6480910]

Ross CA, Ruggiero DA, Park DH, Joh TH, Sved AF, Fernandex-Pardal J, Saavedra JM, Reis DJ. Tonic vasomotor control by the rostal ventrolateral medulla: effect of electrical or chemical stimulation of the area containing $\mathrm{C} 1$ adrenaline neurons on arterial pressure, heart rate, and plasma catecholamines and vasopressin. J Neurosci. 1984b; 4:474-494. [PubMed: 6699683]

Schreihofer AM, Guyenet PG. Identification of $\mathrm{C} 1$ presympathetic neurons in rat rostral ventrolateral medulla by juxtacellular labeling in vivo. J Comp Neurol. 1997; 387:524-536. [PubMed: 9373011]

Schreihofer AM, Guyenet PG. Sympathetic reflexes after depletion of bulbospinal catecholaminergic neurons with anti-D $\beta H$-saporin. Am J Physiol Regul Integr Comp Physiol. 2000; 279:R729-R742. [PubMed: 10938264]

Schreihofer AM, Guyenet PG. The baroreflex and beyond: control of sympathetic vasomotor tone by GABAergic neurons in the ventrolateral medulla. Clin Exp Pharmacol Physiol. 2002; 29:514-521. [PubMed: 12010201]

Schreihofer AM, Stornetta RL, Guyenet PG. Regulation of sympathetic tone and arterial pressure by rostral ventrolateral medulla after depletion of C1 cells in rat. J Physiol. 2000; 529 Pt 1:221-236. [PubMed: 11080264]

Schreihofer, AM., Sved, AF. The ventrolateral medulla and sympathetic regulation of arterial pressure. In: Llewellyn-Smith, IJ., Verberne, AJM., editors. Central Regulation of Autonomic Functions. New York NY, USA: Oxford University Press; 2011. p. 78-97.

Stocker SD, Meador R, Adams JM. Neurons of the rostral ventrolateral medulla contribute to obesityinduced hypertension in rats. Hypertension. 2007; 49:640-646. [PubMed: 17190873]

Stornetta RL. Neurochemistry of bulbospinal presympathetic neurons of the medulla oblongata. J Chem Neuroanat. 2009; 38:222-230. [PubMed: 19665549]

Stornetta RL, Sevigny CP, Schreihofer AM, Rosin DL, Guyenet PG. Vesicular glutamate transporter DNPI/VGLUT2 is expressed by both $\mathrm{C} 1$ adrenergic and nonaminergic presympathetic vasomotor neurons of the rat medulla. J Comp Neurol. 2002; 444:207-220. [PubMed: 11840475]

Strack AM, Sawyer WB, Marubio LM, Loewy AD. Spinal origin of sympathetic preganglionic neurons in the rat. Brain Res. 1988; 455:187-191. [PubMed: 3416186]

Strack AM, Sawyer WB, Platt KB, Loewy AD. CNS cell groups regulating the sympathetic outflow to adrenal gland as revealed by transneuronal cell body labeling with pseudorabies virus. Brain Res. 1989; 491:274-296. [PubMed: 2548665]

Sun MK, Hackett JT, Guyenet PG. Sympathoexcitatory neurons of rostral ventrolateral medulla exhibit pacemaker properties in the presence of a glutamate- receptor antagonist. Brain Res. 1988a; 438:23-40. [PubMed: 2830940] 
Sun MK, Young BS, Hackett JT, Guyenet PG. Rostral ventrolateral medullary neurons with intrinsic pacemaker properties are not catecholaminergic. Brain Res. 1988b; 451:345-349. [PubMed: 2908028]

Trudrung P, Furness JB, Pompolo S, Messenger JP. Locations and chemistries of sympathetic nerve cells that project to the gastrointestinal tract and spleen. Arch Histol Cytol. 1994; 57:139-150. [PubMed: 7520718]

Van Praag H. Neurogenesis and exercise: past and future directions. Neuromolecular Med. 2008; 10:128-140. [PubMed: 18286389]

Van Praag H, Kempermann G, Gage FH. Running increases cell proliferation and neurogenesis in the adult mouse dentate gyrus. Nature Neurosci. 1999; 2:266-270. [PubMed: 10195220]

Verberne, AJM., Llewellyn-Smith, IJ. Neuromethods. New York, NY: Humana Press; 2013. Juxtacellular neuronal labelling, physiological characterisation and phenotypic identification of single neurons in vivo; p. 167-186.

Wang WZ, Gao L, Wang HJ, Zucker IH, Wang W. Tonic glutamatergic input in the rostral ventrolateral medulla is increased in rats with chronic heart failure. Hypertension. 2009; 53:370-374. [PubMed: 19029485]

Zagon A, Smith AD. Monosynaptic projections from the rostral ventrolateral medulla oblongata to identified sympathetic preganglionic neurons. Neuroscience. 1993; 54:729-743. [PubMed: 8332259] 


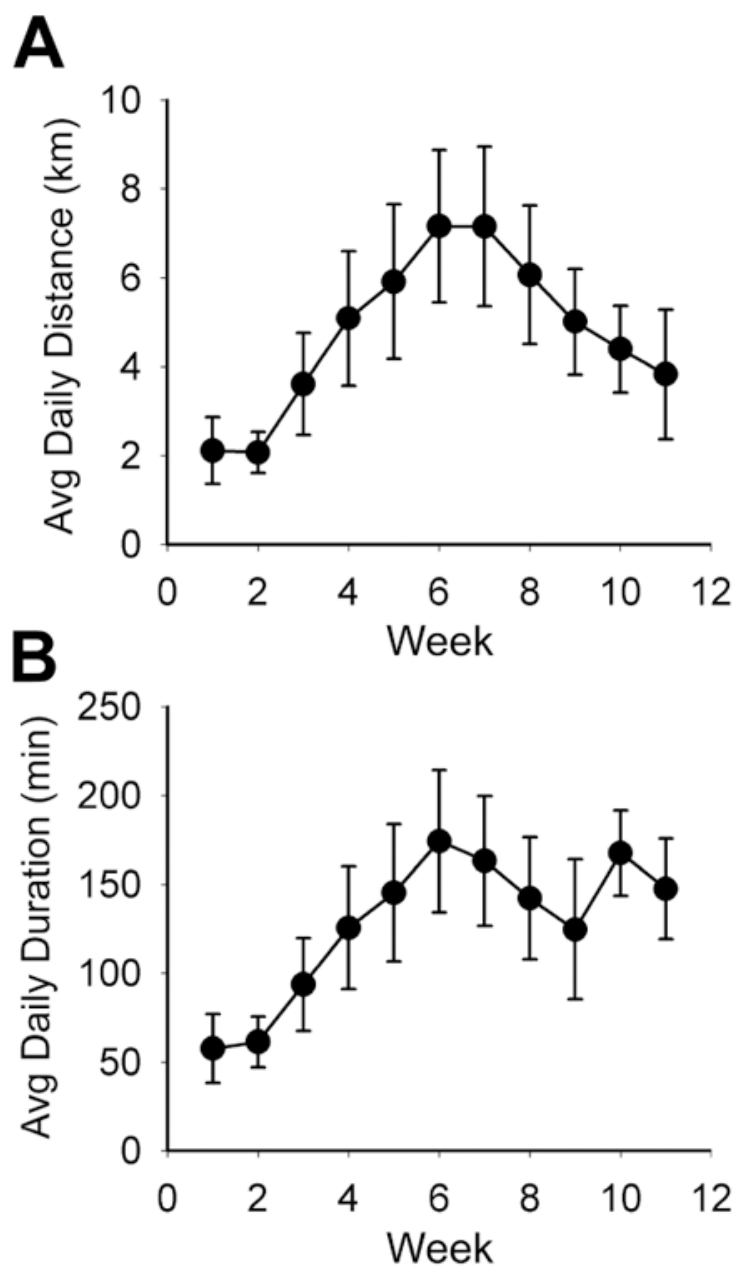

Figure 1. Average weekly running data for physically active rats

Daily running by the six active rats used for morphological analysis. Activity of each rat on its in-cage running wheel was recorded with a bicycle computer. Average daily running distance (A) and duration (B) gradually increased with a peak at weeks 6-7 and then decreased from week 7 to 11 . Average daily running speed did not vary during the course of the study (not shown). At 12 weeks, the rats received injections of CTB into T10 and were perfused seven days later. 


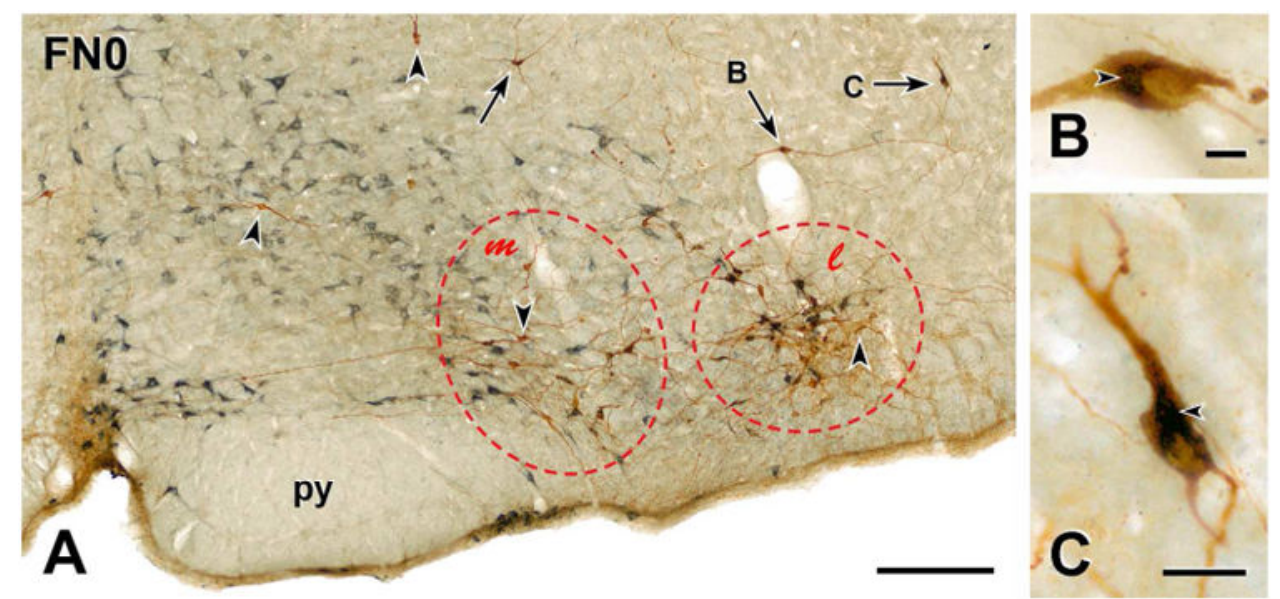

Figure 2. Distribution of bulbospinal catecholaminergic RVLM neurons close to the caudal pole of the facial nucleus

A, Montage of 17 low magnification photomicrographs showing the RVLM very close to the caudal pole of the facial nucleus (FN) from a rat with CTB injections into spinal segment T10 whose activity level was not monitored. Brown TH-immunoreactivity uniformly fills the somata and proximal and distal dendrites of catecholaminergic RVLM neurons. Blue-grey staining due to CTB-immunoreactivity retrogradely transported from the spinal cord is restricted to cell bodies and the portions of proximal dendrites closest to cell bodies. Many of the neurons with immunoreactivity for both TH and CTB occur in a tight cluster (red dashed oval 1) that lies laterally within the RVLM. There are occasional CTB-containing neurons in the group of TH-positive neurons that lies medial to the tight cluster (red dashed oval $\mathrm{m}$ ). Scattered neurons double-stained for TH and CTB (arrows) occur dorsal to the two ventral groups of TH neurons. Two of these double-labeled dorsal neurons (arrows B and C) are shown at higher magnification in panels B and C. Arrowheads, TH-immunoreactive neurons that do not contain CTB-immunoreactivity; py, pyramidal tract. Scale bar, $250 \mu \mathrm{m}$.

B \& C, Higher magnification photomicrographs of the dorsal neurons indicated by arrows B and $\mathrm{C}$ in $\mathrm{A}$. In B, blue-grey CTB-immunoreactivity (arrowhead) occurs only around the nucleus of the retrogradely-labeled neuron. In C, labelling for CTB (arrowheads) extends into the proximal dendrites of the bulbospinal neuron. Scale bars, $25 \mu \mathrm{m}$. 

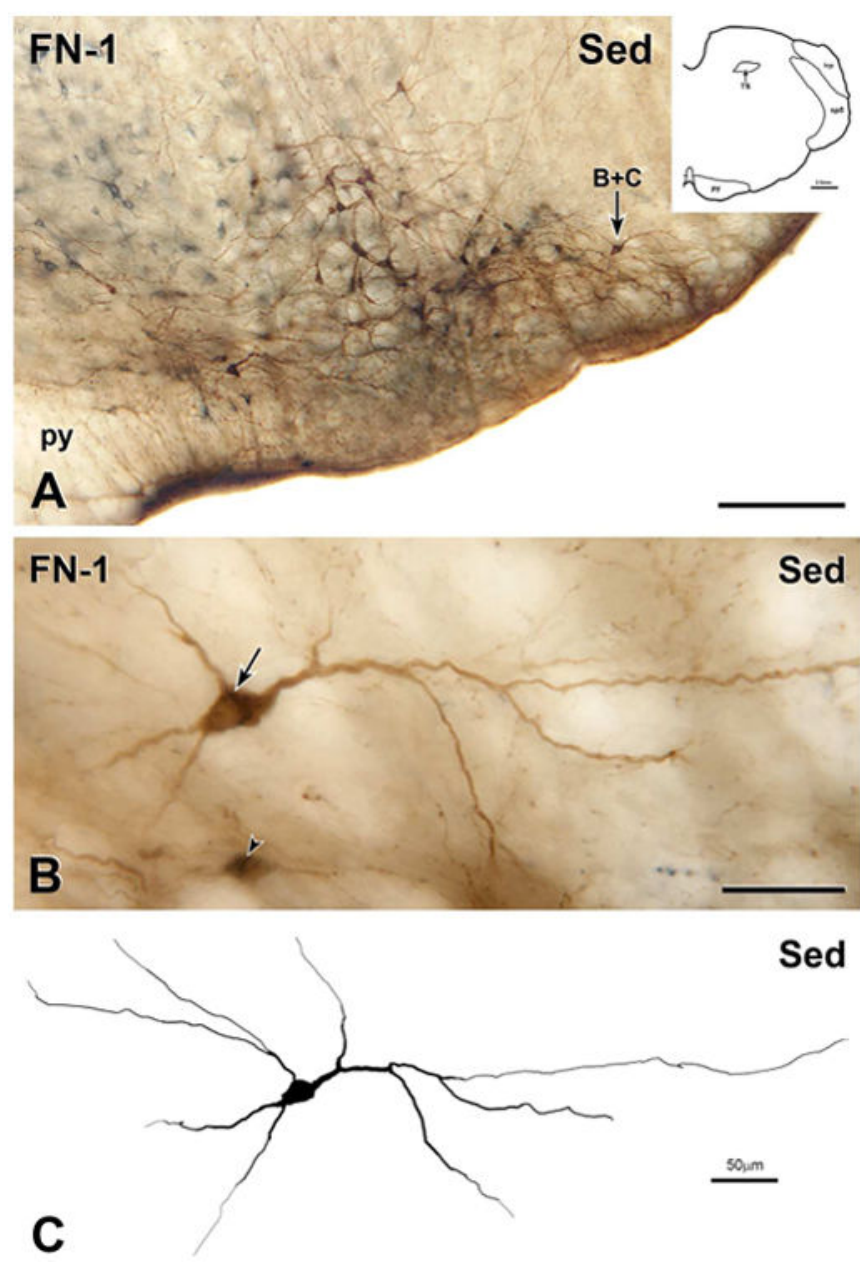

Figure 3. Bulbospinal catecholaminergic neuron from the RVLM of a sedentary rat

A, Montage of 8 photomicrographs showing a section through the RVLM located $150 \mu \mathrm{m}$ caudal to the caudal pole of the facial nucleus (FN-1) from the medulla of a sedentary rat (Sed). The section contains many neurons that are immunoreactive for both CTB (blue-grey) and TH (brown), one of which is indicated by arrow B+C. Scale bar, $250 \mu \mathrm{m}$. Inset, Drawing of FN-1 showing architectonic landmarks. B, Montage of 26 photomicrographs showing the double-labelled neuron indicated by arrow B+C in A. Scale bar, $50 \mu \mathrm{m}$. The cell body of the neuron contains a network of blue-grey staining (arrow), indicating that the neuron has retrogradely transported CTB from the spinal cord. Ventral to the reconstructed neuron, there is another retrogradely labelled neuron showing faint TH-immunoreactivity (arrowhead). Scale bar, $50 \mu \mathrm{m}$. C, Digital reconstruction of the neuron from A and B. Scale bar, $100 \mu \mathrm{m}$. 

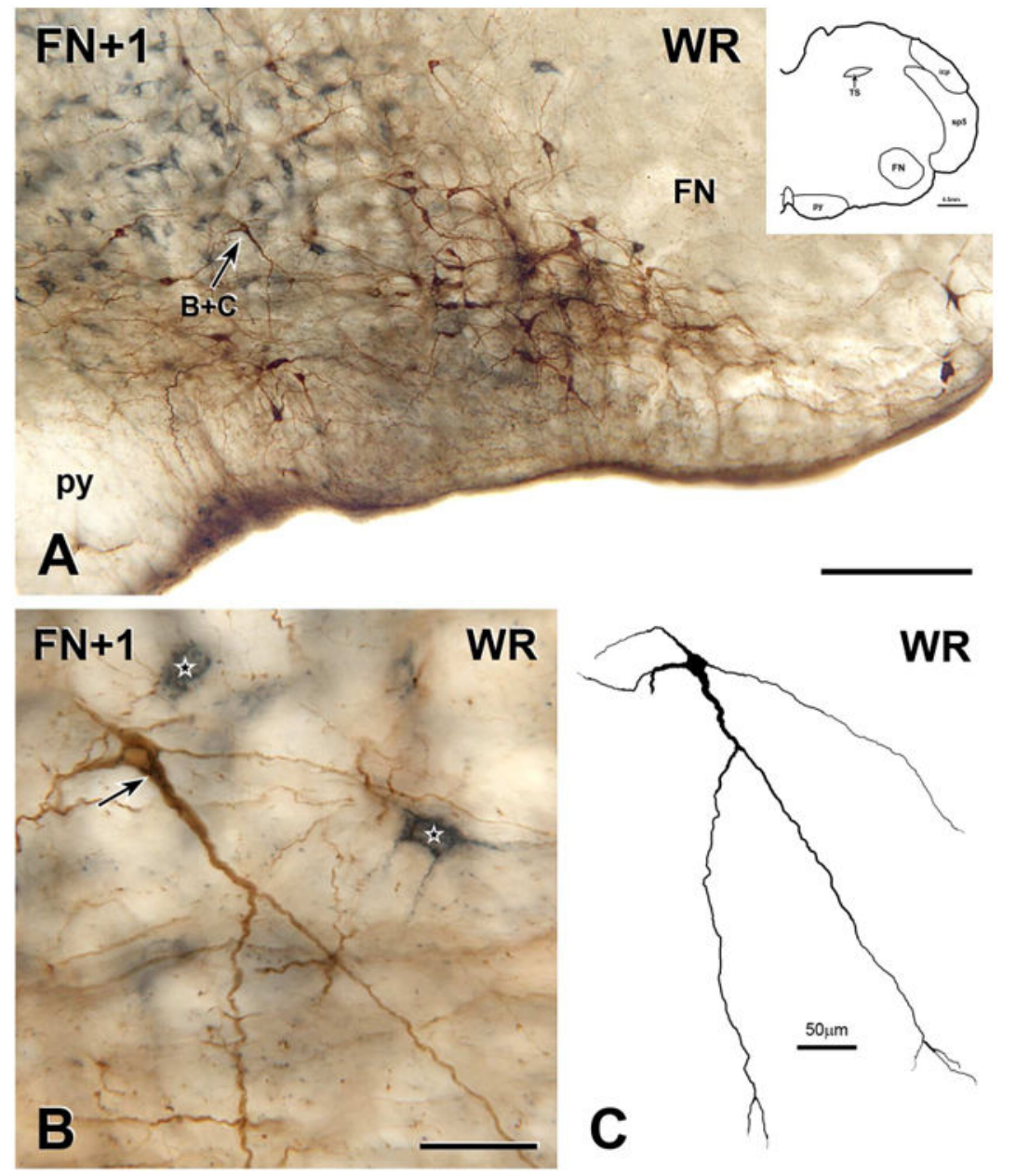

Figure 4. Bulbospinal catecholaminergic neuron from the RVLM of a physically active rat A, Montage of 5 photomicrographs showing a section through the RVLM located $150 \mu \mathrm{m}$ rostral to the caudal pole of the facial nucleus $(\mathrm{FN}+1)$ from the medulla of a rat that ran voluntarily on an in-cage running wheel for 11 weeks. The section contains many neurons that are immunoreactive for both CTB (blue-grey) and TH (brown), one of which is indicated by arrow B+C. Scale bar, $250 \mu \mathrm{m}$. Inset, Drawing of $\mathrm{FN}+1$ showing architectonic landmarks. B, Montage of 11 photomicrographs showing the double-labelled neuron indicated by arrow $\mathrm{B}+\mathrm{C}$ in $\mathrm{A}$. The neuron contains a network of blue-grey staining (arrow) in its cell body and in a thick proximal dendrite, indicating that the neuron has retrogradely transported CTB from the spinal cord. Two other retrogradely labelled neuron (stars) that lacks TH-immunoreactivity lie near to the bulbospinal TH neuron. Scale bar, $50 \mu \mathrm{m}$. C, Digital reconstruction of the neuron in B. Scale bar, $50 \mu \mathrm{m}$. 

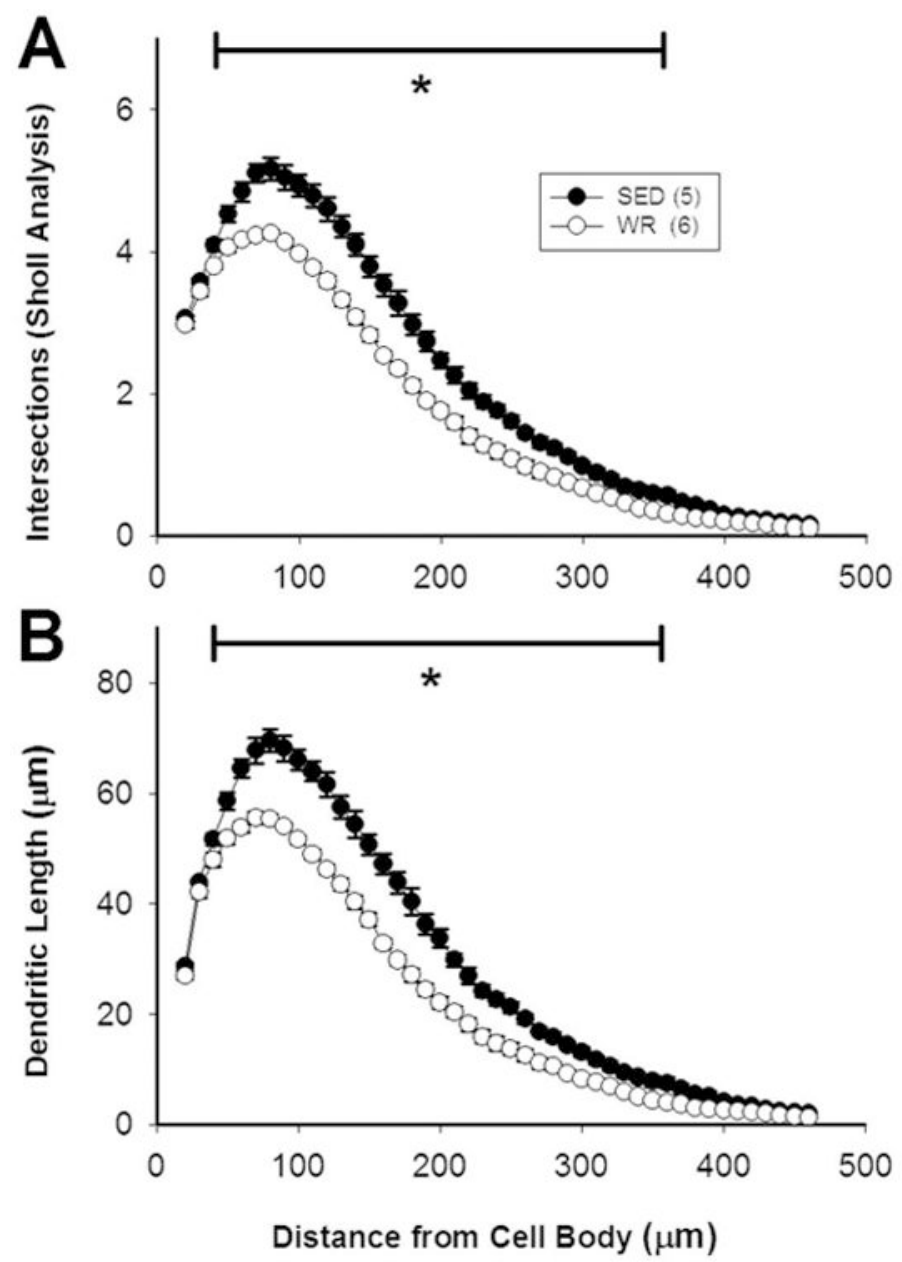

Figure 5. (In)activity-related differences in morphology of dendrites of bulbospinal catecholaminergic RVLM neurons based on Sholl analyses

Morphological data on dendrites obtained via Sholl analyses demonstrated that the length and complexity of the dendrites of TH-positive, CTB-positive RVLM neurons is greater in sedentary rats than in active rats. Data were obtained at $10 \mu \mathrm{m}$ intervals beginning $20 \mu \mathrm{m}$ away from the center of each cell body. Differences in the number of dendritic intersections (A) and dendritic length (B) between sedentary and active rats occurred from 50 to 370 micrometers away from the center of the cell body. ${ }^{*}, \mathrm{p}<0.05$. 

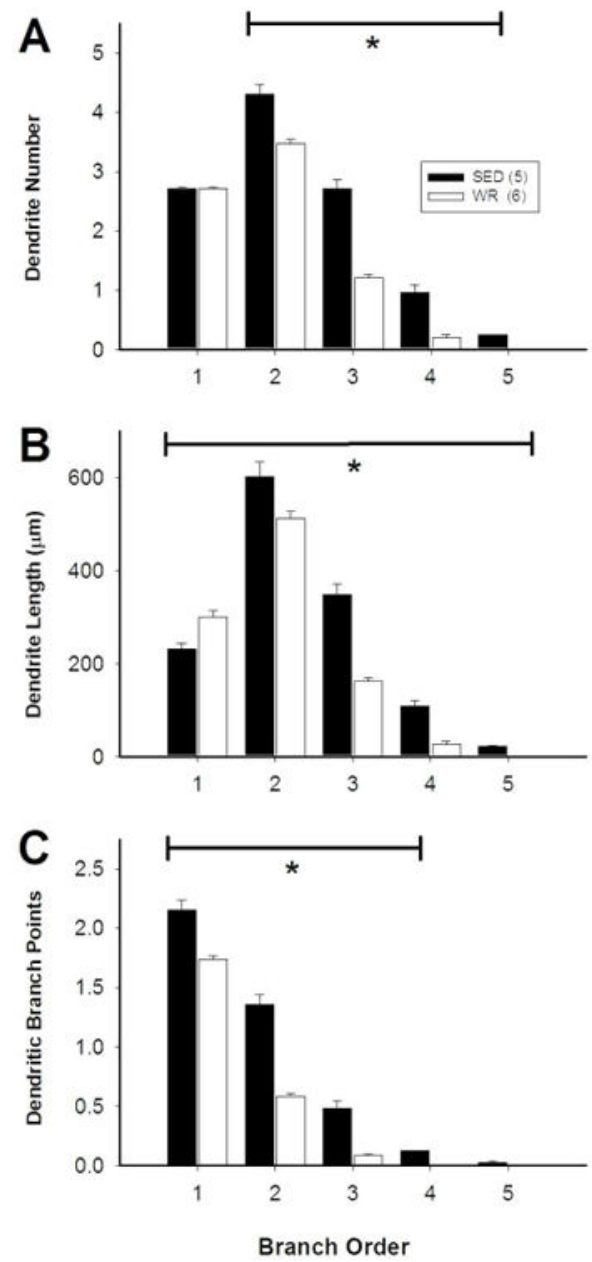

Figure 6. (In)activity-related differences in morphology of dendrites of bulbospinal catecholaminergic RVLM neurons based on branch order Morphological differences between the dendrites of TH-positive, CTB-positive RVLM neurons from sedentary and active rats were not consistent for all types of dendrite. $\mathbf{A}$, The number of primary dendrites was similar between sedentary and active rats, but sedentary rats had more higher-order dendrites relative to active rats. B, Sedentary rats had shorter primary dendrites than active rats, but higher-order dendrites were longer. $\mathbf{C}$, In sedentary rats, $1^{\text {st }}$ to $4^{\text {th }}$ order dendrites had more branches than in active rats. $*, p<0.05$, individual differences between sedentary and active animals. 

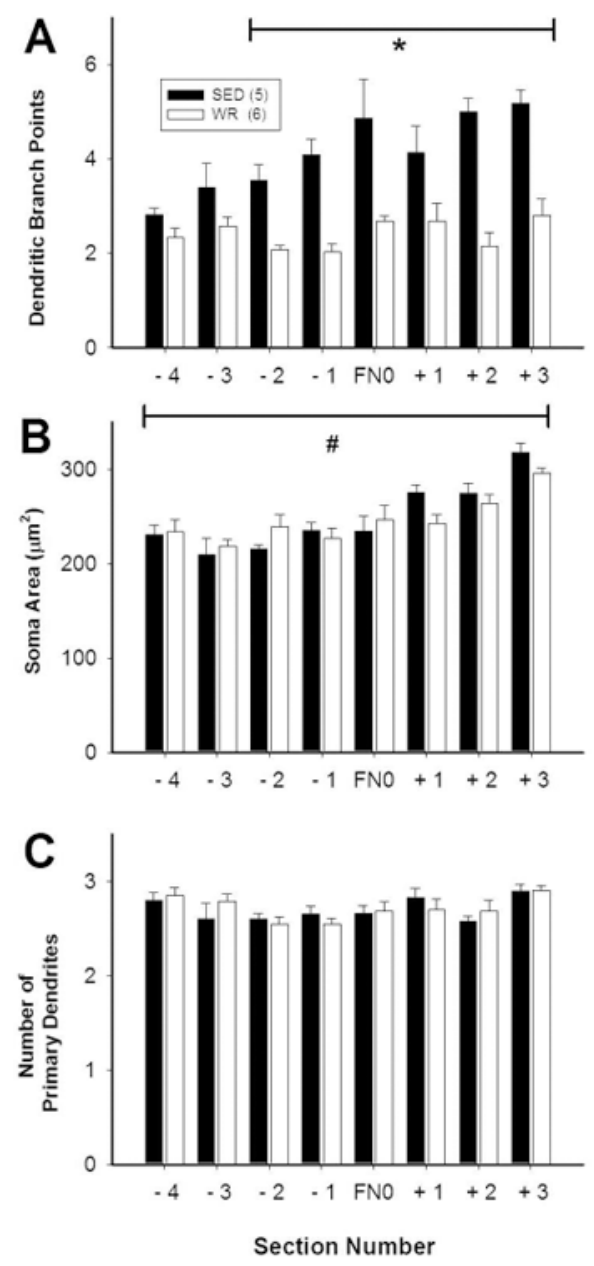

Figure 7. (In)activity-related differences in morphology of dendrites and cell bodies of bulbospinal catecholaminergic RVLM neurons based on rostrocaudal position

Morphological differences between TH-positive, CTB-positive RVLM neurons from sedentary and active rats depended on the position of the neurons relative to the facial nucleus (FN). Each section analyzed was 150 micrometers thick and section FN0 contained the caudal pole of FN. Equal numbers of CTB/TH neurons were reconstructed in eight consecutive sections of the ventrolateral medulla from both groups (i.e. $9.6 \pm 0.2$ vs. 9.2 \pm 0.4 neurons/section in sedentary versus physically rats, respectively). $\mathbf{A}$, In sedentary rats, TH-positive, CTB-positive RVLM neurons had increased branching in sections from 300 micrometers caudal to 450 micrometers rostral of FN0. B, In both groups, cell body size of TH-positive, CTB-positive RVLM neurons was slightly larger in the most rostral section compared to other sections. $\mathbf{C}$, There was no difference in the number of primary dendrites at any level. *, p<0.05, individual differences between sedentary and active animals. \#, $\mathrm{p}<0.05$, main effect of rostrocaudal level on soma area. 


\section{Table 1}

Primary and Secondary Antibodies

\begin{tabular}{|c|l|l|c|}
\hline Antigen & Immunogen & $\begin{array}{l}\text { Manufacturer, species, mono/polyclonal, } \\
\text { catalog \& lot number }\end{array}$ & Dilution used \\
\hline $\begin{array}{l}\text { Primary antibodies } \\
\text { Tyrosine Hydroxylase (TH) }\end{array}$ & $\begin{array}{l}\text { Tyrosine hydroxylase from rat } \\
\text { pheochromocytoma }\end{array}$ & $\begin{array}{l}\text { Millipore, rabbit, polyclonal, Cat. \#AB152, Lot } \\
\text { \#LV 1375881 }\end{array}$ & $1: 1000$ \\
\hline Cholera Toxin Beta Subunit (CTB) & $\begin{array}{l}\text { Cholera Toxin Beta Subunit } \\
\text { isolated and purified from } \\
\text { Vibrio cholerae }\end{array}$ & $\begin{array}{l}\text { List Biological Laboratories, Inc. goat, } \\
\text { polyclonal, Cat \#703, Lot \#7032A7 }\end{array}$ & $1: 100,000$ \\
\hline $\begin{array}{l}\text { Biotinylated secondary antibodies } \\
\text { Rabbit immunoglobulin G }\end{array}$ & & $\begin{array}{l}\text { Jackson ImmunoResearch Laboratories Inc, Cat. } \\
\# 711-065-152, \text { donkey, polyclonal }\end{array}$ & $1: 500$ \\
\hline Goat immunoglobulin G & $\begin{array}{l}\text { Jackson ImmunoResearch Laboratories Inc., Cat. } \\
\# 711-705-065-147, \text { donkey, polyclonal }\end{array}$ & $1: 500$ \\
\hline
\end{tabular}


Table 2

Differences in Neuronal Morphology Between Sedentary and Active Rats

\begin{tabular}{|l|c|c|}
\hline & Sedentary $(\mathbf{n}=\mathbf{5})$ & Active $(\mathbf{n}=\mathbf{6})$ \\
\hline Total Branch Points & $4.16 \pm 0.22$ & $2.40 \pm 0.06^{*}$ \\
\hline Total Dendrite Length $(\mathrm{m} \mu)$ & $1319 \pm 49$ & $991 \pm 25^{*}$ \\
\hline Dendrite Surface Area $\left(\mathrm{m}^{2}\right)$ & $6142 \pm 237$ & $4750 \pm 136^{*}$ \\
\hline Total Intersections & $99 \pm 3.8$ & $77 \pm 1.8$ \\
\hline Primary Dendrites & $2.71 \pm 0.02$ & $2.71 \pm 0.03$ \\
\hline Cell Body Area $\left(\mathrm{m}^{2}\right)$ & $251 \pm 6.8$ & $246 \pm 3.7$ \\
\hline Cell Body Perimeter $(\mathrm{m} \mu)$ & $76.9 \pm 0.6$ & $77.1 \pm 1.4$ \\
\hline Cell Body Aspect Ratio & $1.90 \pm 0.03$ & $1.90 \pm 0.02$ \\
\hline
\end{tabular}

Values are expressed as means \pm SE; n, number of animals. km/d; kilometers per day; Cell Body Aspect Ratio, length of the cell body (long axis) divided by the width of the cell body (short axis).

,, $\mathrm{p}<0.05$ between sedentary and active animals. 